\title{
Entfernung der Colatorien aus der Receptur;
} ron

Dr. Moh r.

Die Colatorien sind das unangenehmste und unreinlichste Geräth in dem Laboratorium und der Officin. Wie viel Sorgfalt man auch auf die Unterscheidung derselben durch bunte Schleifen, abgeschnittene Ecken und ähnliche Dinge verwendete, wie sehr man auch bemüht war, die Colatorien für gefärbte, stark riechende und farblose Decocte und Infusa in verschiedenen Kästen getrennt zu halten, in der Wirklichkeit zeigten sich diese Vorsichtsmaassregeln als vollkommen illusorisch. Da die Colatorien nicht immer gleich gereinigt werden können, sondern zu einer bestimmten Zeit oder wenn grössere Mengen zusammengekommen sind, so müssen sio doch bis zu dieser Zeit aufbewahrt werden. Hat man nicht ebenfalls drei verschiedene Töple zum Aufbewabren derselben, so ist jede fernere Trennung ganz unnütz, indem sie sich mit den Resten der Species und des Decocts zusammenliegend mit Farbe und Geruch wechselseilig versehen. Allein das reinste Colatorium hat nach einer gewissen Zeit des Gebrauches eine hässliche braune Farbe angenommen, und man kann es nicht wagen, vor den Augen der Kunden dasselbe zu gebrauchen. Die Art des Gebrauches ist unter allen Umständen, selbst bei einem ganz neuen Colatorium, unangenehm, indem die abrinnende Flüssigkeit die Hände zum Theil benetzt und davon in die Mensur abläuft.

Die Colatorien sind als solche ganz unverbesserlich, sie müssen geradezu entfernt werden.

Man ersetzt sie vollkommen durch metallene Seiher, wie sie in den Caffeemaschinen gebraucht werden. Das Verseihen des Caffees beweiset schon, dass sie zu die-

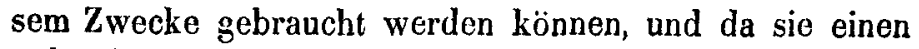
pulverförmigen Körper zurückhalten, so müssen sie um so mehr also einen faserigen oder blättrigen abscheiden. 
Wenn auch die kleinsten Stäubchen eines gröblichen Pulvers, eines geschnittenen Krautes im trocknen Zustande durch die Poren des Seihers dringen können, so findet dies doch nicht mehr im geschwellten Zustande statt.

Die Seiher werden aus verzinntem Eisenblech angefertigt. Man hat solche mit runden und mit langen Löchern. Letztere sind unbedenklich vorzuziehen, indem sie mit derselben Mühe angefertigt, eine weit grössere filtrirende Fläche darbieten. Auch verstopfen sich die langen Löcher weniger leicht als die runden. Diese Oeffnungen werden mit stählernen Punzen auf einer Unterlage von Zinn hera usgeschlagen, wodurch die Ränder der Oeffnungen nach unten aufgetrieben erscheinen, wie an einem Reibeisen. Auf einem polirten stählernen Ambosse werden diese Ränder wieder beigetrieben und dadurch zugleich die Oeffnung soweit verengert, als es zum Zwecke nothwendig ist. Durch dieses Beischlagen kann man jede beliebige Verengerung der Oeffnungen hervorbringen. Die Länge einer solchen Spaltes ist ungefähr 6 Millim. (3 Linien) und die lichte Weite derselben $1 / 3$ Millim. $(1 / 6$ Linie $)$. Der Seiher hat einen Durchmesser von 3 bis 4 Zoll. Er passt genau auf den obern Rand eines Seihepfännchens, welches, wenn der Seiher Zoll Durchmesser hat, eine Tiefe von $2 \frac{1}{2}$ Zoll hat. Es nimmt alsdann ein Decoct bis zu 14 Unzen auf.

Die Flüssigkeit rinnt zunächst in das untergestellte Pfännchen. Hierin lässł man sie einige Augenblicke stehen, um das abzusetzen, was sich noch absetzen kann: dasselbe muss bekanntlich auch bei wollenen Colatorien geschehen; indem feiner Staub auch hier durch die Poren durchläuft und nur durch Absetzen entfernt werden kann. Damit aber nichts an der Colatur fehle, muss dieses Absetzen vor dem Eingiessen und Abmessen in die Mensur geschehen. Die etwas flache Gestalt des Seihepfännchens ist auch zum Absetzen geeigneter als eine Mensur, weil die Pulver schneller den Boden erreichen.

Das Auspressen ist in den meisten Fällen kaum nothArch. d. Pharm. CII. Bds. 1. Hft. 
wendig, indem die Flüssigkeit auf dem Seiher schneller und vollständiger abrinnt als auf dem Colatorium. Bei letzterem ist man immer in Eile, weil man so wenig auf einmal aufgiessen kann, und desshalb das Ablaufen abwarten muss. Auch hielt die Substanz des Colatoriums ungepresst viel Flüssigkeit in ihren Poren zurück, was der Seiher natürlich nicht thut. Hölzer, Wurzeln und Rinden geben durch Auspressen fast gar keinen Nachlauf; Kräuter, Blumen und Blätter geben etwas. Man drückt mit einer flachen Blechscheibe, die in der Mitte einen Stiel hat, sanft auf. Was hierdurch nicht abfliesst, muss in den Species sitzen bleiben. Diese erscheinen aber auf diese Weise ausgedrückt vollkommen eben so trocken, als wenn sie im Colatorium ausgerungen wären.

Alle Species zu Decocten und Infusionen sollen durch Abschlagen vorher von Staub befreit sein. Die Vorzüge der metallenen Seiher sind augenfallig. Der wesentlichste ist die Reinlichkeit. Der Seiher nimmt weder Farbe noch Geruch von den Infusionen oder Decocten an, und kann sie desshalb auch nicht an andere nachfolgende ibertragen, wenn er mil reinem Wasser abgespult worden ist. Die Unterscheidung der Seiher für gefärbte und ungefärbte Decocte ist ganz unwesentlich, und desshalb kann aus deren Vernachlässigung auch kein Uebelstand entstehen. Man kann auf ein Chinadecoct augenblicklich eine Mandelmilch folgen lassen, ohne dass man im Stande wäre, davon die geringste Veränderung in Farbe und Geruch wahrzunehmen. Beim Durchseihen berüht die Fluissigkeit niemals die Hände, was dem Patienten nur sehr angenehm sein kann. Man kann das Durchseihen, ohne Widerwillen zu erregen, vor den Kunden ausfuhren. Die Seiher lassen sich leicht reinigen. Nachdem man die Species herausgeschüttet hat, lässt man einen starken Strahl Wasser in den verkehrt gehaltenen Seiher stürzen. Es spült alle Reste von Pulvern aus den Poren, und wenn man den Seiher durch heftiges Schwenken etwas abgetrocknet hat, lässt er sich sogleich wieder gebrauchen. Zwei Seiher 
leisten mehr Dienste als 24 Colatorien. Man erspart das Trocknen der Colatorien und die Kosten ihrer Neubeschaffung, abgesehen davon, dass ehe sie wirklich entfernt werden, durch Bersten und Flicken derselben schon viel Verdruss veranlasst worden ist.

Für einige besondere Fälle bemerke ich noch Folgendes. Altheewurzelschleim von geschnittenen Wurzeln läuft sehr klar und schnell durch. Sind die Wurzeln gemahlen oder gröblich gestossen, so versetzen sich die Löcher sehr leicht. Man befördert das Durchgehen wesentlich, wenn man mit einem Spatel leichte Schläge auf den Boden des Seihers giebt. Je ruhiger eine Flüssigkeit abrinnt, desto klarer ist sie. Der Altheeschleim sieht wie frisches Eiweiss aus, und ist vollkommen durchsichtig. Er darf niemals gepresst werden, wodurch er unvermeidlich trübe wird.

Leinsamenschleim, der so schwicrig durch Colatorien geht, rinnt ganz klar und leicht ab.

Der abgeschlagene Staub von Flores Verbasci, heiss infundirt, gab ein ganz klares Infusum.

Samenemulsionen rinnen etwas schwieriger durch, wenn man die Substanz sogleich mit auf den Seiher giebt, dagegen sehr leicht, wenn man die reine Milch von oben ahgiesst. Man hilft mit leichten Schlägen eines Spatels auf den Boden des Seihers nach. Infusionen selbst schleimiger Wurzeln, wie Rhabarber und Gentiana, gehen ganz klar und schnell durch. Von ganzen oder geschnittenen Blättern, wie $\boldsymbol{H} b$. Menthae pip. und crisp., Melissae, Fol. Senn. und ähnliche, ist der Aufguss so klar, wie von grünem Thee. Dass alle holzigen und faserigen Substanzen sich ebenfalls zur Abseihung eignen, konnte man schon von vornherein voraussehen.

Ich zweifle nicht daran, dass schon manche Apotheker sich hier und dort ähnlicher Vorrichtungen statt der Colatorien bedienen; allein die metallenen Seiher sind noch nicht allgemein empfohlen, noch weniger allgemein im Gebrauch. 